\title{
Classification and Management of Mandibular Condyle Fractures in a Tertiary Health Center
}

\author{
Babatunde O. Akinbami ${ }^{*}$, Oladimeji A. Akadiri \\ Department of Oral and Maxillofacial Surgery, Dental Center, University of Port Harcourt Teaching Hospital, \\ Port Harcourt, Nigeria \\ Email: *akinbamzy3@yahoo.com
}

Received May 16, 2013; revised June 18, 2013; accepted June 26, 2013

Copyright (C) 2013 Babatunde O. Akinbami, Oladimeji A. Akadiri. This is an open access article distributed under the Creative Commons Attribution License, which permits unrestricted use, distribution, and reproduction in any medium, provided the original work is properly cited.

\begin{abstract}
Background: Condyle fractures are not common but could lead to detrimental effects of growth disturbance of the mandible, ankylosis of temporomandibular joint and facial asymmetry especially in children, if not promptly and adequately managed, the aim of this study was to document our experience in the management of mandibular condyle fractures. Method: The fractures were classified based on the age of the patient, unilateral/bilateral, location on the condyle, presence of displacement and dislocation, for those displaced, whether there was medial or lateral overlap, and features presented. Treatment done for each patient was documented. Both clinical and radiological assessments were done to ascertain the outcome of treatment. Result: 11 patients presented with 14 condyle fractures, 3 patients with bilateral and 8 with unilateral condyle fractures out of which 5 cases were on the right side. Age range of patients was between 13 and 44 years with a mean (SD) of 25.3 (10.7) years. Nine (81.8\%) of the patients were males and $2(18.2 \%)$ were females. Eight (72.7\%) of the patients with condyle fracture had associated fractures affecting other sites of the mandible while 3 (27.3\%) patients had isolated condyle fractures. Intracapusular fractures recorded were 2 (14.2\%), while extracapsular accounted for 12 (85.8\%) cases. Conservative treatment was not applied in any patient, 9 (81.8\%) patients had IMF and 2 (18.2\%) patients had ORIF. Conclusion: Most fractures of the condyle were extracapsular and, closed surgical treatment (IMF) was very useful to manage most of the cases.
\end{abstract}

Keywords: Classification; Management; Condyle; Fractures

\section{Introduction}

Fractures of the condyle of the mandible are rare [1]. Condyle fracture is a protective mechanism which prevents fracture of the base of the skull [2]. It is commonly an associated fracture with fractures of the body, symphysis or parasymphysis of the mandible due to transmission of forces following impacts on these sites. It can also occur in isolation as a consequence of direct impact. These fractures have been classified as intracapsular or extracapsular, unilateral or bilateral and, head, neck (high or low) subcondylar fractures based on the site [3]. In addition, according to Lindahl, fractures of the condyles can be classified into six, vertical slit of the head (type I), horizontal break but mildly or not displaced (II), displacement of the segments (III), there may be medial overlap (IV) or lateral overlap (V) of the displaced smaller proximal segment and a possible partial or com-

\footnotetext{
"Corresponding author.
}

plete dislocation of the segment [3]. Rarely, fractures of the condyle may also be communited (type VI) especially with gunshot injuries [3].

Aesthetics and restoration of function such as mouth opening and mastication are important considerations in the management of these fractures [4]. Others include swallowing, occlusion, and control of symptoms like pain, swelling and deviation [4]. Treatment ranges from observation, jaw exercises to closed or open interventions [5]. However in cases that require treatment many surgeons have favored closed treatment to open treatment in order to prevent some complications of open treatment [6]. The purpose of this article was therefore to document our experience in the management of mandibular condyle fractures.

\section{Patients and Methods}

All consecutive patients that presented with fractures of 
the condyle of the mandible to casualty or oral and maxillofacial department of the University of Port Harcourt Teaching hospital between May 2006 and December 2012 were included in the study. Informed consent was obtained from the patients/relatives and the study was approved by the hospital ethics and research committee. The gender and age of the patients as well as the time of presentation, site, side and associated symptoms like pain, swelling, bleeding from the ear and deviation of the mandible on opening or closing, restriction of mouth opening and inability to close were retrieved from the hospitals' records and documented. Conventional Posterior Anterior view, oblique lateral views of the mandible or reversed Town's view of the skull were taken to confirm the specific sites, degree of displacements, overlap or dislocation. The fractures were classified based on age of the patient, unilateral/bilateral, location on the condyle, presence of displacement and dislocation, for those displaced, whether there was medial or lateral overlap, and features presented. Treatment done for each patient was documented and was categorized as conservative treatment, closed surgical and open surgical treatment. The outcome of treatment was also documented. Both clinical and radiological assessments were done to ascertain the outcome of treatment. Favorable clinical outcome was based on resolution of symptoms, restoration of occlusion, unrestricted movements of the lower jaw, absence of deviation or minimal deviation, facial symmetry and improved inter-incisal distance. Radiographic outcome was based on suitable alignment of the proximal and distal segments and reduced fracture gap.

\section{Result}

A total of 34 patients with mandibular fractures of varying sites were managed in our department out of which 11 (32.4\%) patients presented with 14 condylar fractures, (Tables 1-3) 3 (27.3\%) patients with bilateral and 8 (72.7\%) with unilateral condylar fractures out of which 5

Table 1. Biodata and characteristics of the first consecutive patients.

\begin{tabular}{|c|c|c|c|c|c|c|c|c|}
\hline S/No & Sex/Age & Side & Site & Displacement & cause & features & Treatment & Outcome \\
\hline 1. & $\mathrm{M} / 40$ & Both & $\begin{array}{c}\text { RT Sub } \\
\text { LT Low Neck }\end{array}$ & $\begin{array}{l}\text { Lateral overlap(V) } \\
\text { Displaced(III) }\end{array}$ & RTA & Anterior open bite & $\begin{array}{l}\text { Closed reduction } \\
\text { and IMF }\end{array}$ & Satisfactory \\
\hline 2. & $\mathrm{M} / 33$ & RT & Low Neck & Medial overlap (IV) & RTA & $\begin{array}{c}\text { Posterior open } \\
\text { bite/gagging }\end{array}$ & $\begin{array}{l}\text { Closed reduction and } \\
\text { IMF }\end{array}$ & Satisfactory \\
\hline 3. & $\mathrm{M} / 15$ & RT & Low Neck & Medial overlap(IV) & Fall & $\begin{array}{c}\text { Posterior open } \\
\text { bite/gagging }\end{array}$ & $\begin{array}{l}\text { Closed reduction and } \\
\text { IMF }\end{array}$ & Satisfactory \\
\hline 4. & $\mathrm{M} / 16$ & RT & Low Neck & Medial overlap(IV) & RTA & $\begin{array}{c}\text { Posterior open } \\
\text { bite/gagging }\end{array}$ & ORIF & Satisfactory \\
\hline
\end{tabular}

*Subco-subcondyle, LT-left, RT, right.

Table 2. Biodata and characteristics of the second consecutive patients.

\begin{tabular}{|c|c|c|c|c|c|c|c|c|}
\hline S/No & Sex/Age & Side & Site & Displacement & cause & features & Treatment & Outcome \\
\hline 5. & $\mathrm{M} / 13$ & LT & Head & Mildly displaced(II) & Fall & $\begin{array}{l}\text { Posterior open } \\
\text { bite }\end{array}$ & $\begin{array}{l}\text { Closed reduction } \\
\text { and IMF }\end{array}$ & Satisfactory \\
\hline 6. & $\mathrm{M} / 21$ & Both & $\begin{array}{c}\text { RT } \\
\text { Subco } \\
\text { LT Low Neck }\end{array}$ & $\begin{array}{c}\text { Medial overlap (IV) } \\
\text { Displaced(III) }\end{array}$ & RTA & $\begin{array}{c}\text { Posterior open } \\
\text { bite/gagging }\end{array}$ & $\begin{array}{l}\text { Closed reduction } \\
\text { and IMF }\end{array}$ & Satisfactory \\
\hline 7. & $\mathrm{~F} / 26$ & RT & Low Neck & Medial overlap(IV) & RTA & $\begin{array}{c}\text { Posterior open } \\
\text { bite/gagging }\end{array}$ & $\begin{array}{l}\text { Closed reduction } \\
\text { and IMF }\end{array}$ & Satisfactory \\
\hline 8. & $\mathrm{~F} / 15$ & RT & Low Neck & Displaced(III) & RTA & $\begin{array}{c}\text { Posterior open } \\
\text { bite/gagging }\end{array}$ & ORIF & Satisfactory \\
\hline
\end{tabular}

*Subco-subcondyle, LT-left, RT, right.

Table 3. Biodata and Characteristics of the third consecutive patients.

\begin{tabular}{|c|c|c|c|c|c|c|c|c|}
\hline S/No & Sex/Age & Side & Site & Displacement & cause & features & Treatment & Outcome \\
\hline 9. & $\mathrm{M} / 23$ & Both & $\begin{array}{c}\text { LT Subc } \\
\text { RT Low } \\
\text { Neck }\end{array}$ & $\begin{array}{c}\text { Lateral overlap(V) } \\
\text { Displaced (III) }\end{array}$ & RTA & $\begin{array}{l}\text { Anterior open } \\
\text { bite }\end{array}$ & $\begin{array}{l}\text { Closed reduction } \\
\text { and IMF }\end{array}$ & Satisfactory \\
\hline 10. & $\mathrm{M} / 44$ & $\mathrm{RT}$ & Subco & Medial overlap(IV) & RTA & $\begin{array}{c}\text { Posterior open } \\
\text { bite/gagging }\end{array}$ & $\begin{array}{l}\text { Closed reduction } \\
\text { and IMF }\end{array}$ & Satisfactory \\
\hline 11. & $\mathrm{M} / 32$ & LT & Low Neck & Medial overlap (IV) & Fall & $\begin{array}{c}\text { Posterior open } \\
\text { bite/gagging }\end{array}$ & $\begin{array}{l}\text { Closed reduction } \\
\text { and IMF }\end{array}$ & Satisfactory \\
\hline
\end{tabular}

*Subco-subcondyle, LT-left, RT, right. 
(45.5\%) cases were on the right side. Age range of patients was between 13 and 44 years with a mean (SD) of 25.3 (10.7) years. Nine $(81.8 \%)$ of the patients were males and $2(18.2 \%)$ were females. Eight $(72.7 \%)$ of the patients with condyle fracture had associated fractures affecting other sites of the mandible while 3 (27.3\%) patients had isolated condyle fractures. (Tables 1-3) Intracapusular fractures recorded were 2 (14.2\%) \{head was 1 (7.1\%) and upper neck was $17.1 \%)\}$ while extracapsular accounted for 12 (85.8\%) cases, the lower neck of the condyle was the site most commonly involved with $9(64.3 \%)$ cases while the subcondyle was affected in $3(21.5 \%)$ cases respectively. All our patients presented within 24hrs of injury and 9 (81.8) \% were due to road traffic accident. Plain radiographs revealed gross displacements with medial overlap (type IV) in 7 (50\%) of the 14 condylar fractures, lateral overlap (type V) in 2 (14.2\%), there was moderate displacement (type III) without overlap in 4 (28.6\%), mild displacement (type II) was present in $1(7.1 \%)$ of the cases. When there was bilateral fracture anterior open bite and gagging of occlusion on both posterior sides were the prominent occlusal derangements. All the unilateral cases with moderate to gross displacements presented with features posterior open bite on the normal side and gagging on the affected side with deviation of the jaw to the affected side. Such features were slightly altered when there were grossly displaced fractures of other sites of the mandible. Conservative treatment (medication, jaw exercise and observation) was not indicated in any patient, while 9 (81.8\%) patients had closed treatment with intermaxillary fixation using arch bars and 1 (9.2\%) patient each had open reduction and internal fixation with bone plates and transosseous wires respectively. The submandibular approach was used for both patients. The patients were followed-up for about 2 months postoperative and there was satisfactory outcome in all the cases with complete remission of pain, swelling and restriction in mouth openings, correction of occlusal derangements and deviation which was further improved with jaw exercise for at least 2 to 3 weeks. Alignment of the segments was satisfactory in all the patients within 6 - 8 weeks following treatment.

\section{Discussion}

Fractures of the mandibular condyle account for 19\% $52 \%$ of all fractures of the mandible in the literature, in our study [1-4], it was about 32.4\%. Despite the fact that the condyle is the weakest part of the mandible, fracture of this portion of the mandible from direct impact is not very common because of the protective and cushioning effects of the muscles, meniscus, ligament, capsule and surrounding bones [2]. However indirect impact as in cases of contra-coup and parade ground fractures are commoner. Such fractures to the condyle in most sce- narios serve as a protective mechanism preventing transmission of force and injury to the base of the skull [3]. Generally, bilateral cases which occur with impact on the chin are much fewer than unilateral cases as observed also in our study [4]. There is no side predilection in condyle fractures as this is determined by the mechanics of injury, the position of patient and impact direction. Two classical features of intracapsular fracture involving the head or upper neck of the condyle are bleeding from the ear and supramastoid hematoma (Battle's sign) [5-8], however we did not study observe these features in our study and this may be attributed to the fact that most of our cases involved the extracapsular sites (lower neck and subcondylar) of the condyle in contrast to other studies with higher figures for intracapsular fractures [9,10]. In addition, the few cases of fractures of the head and upper neck may not be displaced backwards at the point of impact; therefore the bony external acoustic meatus and mastoid bone were not traumatized. Other features of deranged occlusion and deviation of the mandible in unilateral fractures dominated our findings in this study and this was similar in reports from other parts of the globe [11-13]. Anterior open bite is classical in cases of bilateral fractures that are moderately or grossly displaced with either medial or lateral overlap (type III to VI) based on Lindahl's classification [14]. This is due to upward pull of the lower segment by the muscles of mastication and eventual telescoping of the upper condyle segment. Based on the degree of displacement, half of the fractures documented in this study are classified as type IV with medial overlap of lower mandibular segment by the fragmented upper condylar segment. This is not surprising, because the upper condyle segment is usually pulled medially by the lateral pterygoid muscle.

The immediate objectives of treatment that must be achieved include stabilization of the patient following ABCDE protocol that is airway control, breathing, circulation, CNS dysfunction, elimination of pain and swelling, and achievement of close to normal occlusion [15]. There are controversies regarding the choice of treatment amongst many surgeons but various factors such as the age of the patient, duration of fracture, specific site of fracture on the condyle, degree of displacement, time of presentation and availability of funds and resources are relevant considerations. Long-term objectives are aimed at restoration of form and function of the jaw and facial skeleton [16]. Definitive treatments to achieve these objectives are based on the principle of reduction, fixation/immobilization of the jaw/jaws. Broadly, treatment can be closed reduction and IMF with arch bars if available or eyelet wires under GA or LA especially when close to anatomical reduction is achievable [17]. It can also be closed reduction and external fixation under GA (frames and cap splint) if materials are available espe- 
cially for communited fractures which may be due to gunshots. Open reduction and internal fixation (ORIF) with plates (rigid) under GA offers the best option especially for gross displacements and patient who do not want their mouth closed for a long period [18]. Open reduction and transosseous wires (semi-rigid) are useful when plates are not available [18].

Treatment should be done early enough to minimize pain, swelling, prevent infection and enhance healing with minimal callus, but it is better done when patients are stable and respiration is not compromised [19]. Most condylar fractures are treated with closed reduction and intermaxillary fixation with arch bars using stainless steel wires or elastic bands for immobilizing the jaws for about 2 - 6 weeks depending on the age, time of presentation, site/type of fracture, and severity of symptoms [20].

Fresh cases unilateral or bilateral extracapsular fractures in children or adults require IMF for 3 - 4 weeks while cases of unilateral or bilateral extracapsular fractures (lower neck and subcondylar) that have been left untreated for sometime ( $>1$ week) will need slow rubber traction with a posterior bite plane to correct the contralateral or anterior open bite caused by the marked overlap of the fracture segments due to muscle spasms [21]. This is placed on the teeth prior to intermaxillary fixation with elastics bands around the hooks of the arch bars.

When presentation is more than 1 month, consolidation has begun and there will need for open reduction and internal fixation. These were not applicable in our study because all the patients presented within 24 hrs of injury.

Fractures affecting the head and upper neck are confined within the capsule (intracapsular) and displacements are usually minimal and most of these can be treated with IMF in both children and adults $[8,9,22]$. However in longstanding cases that has malunited, ORIF may be indicated to correct the deformities and asymmetry especially in adults, most surgeons tend to avoid ORIF in children to prevent ankylosis, facial nerve damage and most importantly, growth disturbance $[17,23]$. Scar formation is another complication in Africans which can be mitigated by endoscopic approach [24]. Dahlstrom et al. [1] in their 15 years follow-up study on condylar fractures treated by closed reduction, also documented that there were no major growth disturbances amongst the children and the function of their masticatory system was good. There are no arguments against closed treatment in children except that open treatment is preferred for low level/subcondylar and dislocated fractures because of improved functional outcome associated with it.

Furthermore, for undisplaced intracapsular fractures without symptoms like pain, swelling and deviation children and adults, conservative approach (no fixation) with jaw exercises using tongue blades, acrylic or wooden screws for 2 weeks may be sufficient. Frequently, because fracture to the head or high neck is intracapsular, it is not usually displaced $[8,9]$. If there is no symptom, observation of the patient and, assessment of mouth opening and temporomandibular joint every 2 month with serial TMJ X-rays [8,9].

If pain and swelling is present, recommended drugs are (Augmentin 375 - $625 \mathrm{mg} 8$ hrly for 5 days and analgesics like paracetamol $500 \mathrm{mg} 8$ hrly for 3 days or tramadol 25 - $50 \mathrm{mg} 8$ hrly for 3 days for more severe pains depending on the age. If there is restriction of mouth opening and deviation then conservative therapy with jaw exercise using tongue blades, acrylic or wooden screws for 2 weeks may be sufficient (no fixation), however this likely to be painful. So patient must be covered with analgesics or done under relative analgesia if facility is available. If symptoms persist after 3 days, then closed reduction and IMF with eyelets or acrylic cap splints for 1 - 2 weeks followed by jaw exercise is applicable [25].

If there is displacement in head or high neck fractures, especially when accompanied with other symptoms, then the fracture is treated with closed reduction and IMF for 2 - 4 weeks followed by jaw exercise, analgesics, antibiotics for 1week and postoperative follow-up and review with serial X-rays [26]. Open reduction and internal fixation is not indicated for undislocated fractures of condyle head and upper neck in children because of reasons already mentioned and technical difficulties in manipulating the small upper condyle segments [27].

Absolute indications for ORIF include lateral overlap displacements in extracapsular fractures, fractures associated with dislocations of the condylar head, failure to achieve satisfactory occlusion following closed reduction and, presence of foreign bodies in the joint [28]. However ORIF can be done in a patient who has no dentition and where a splint is unavailable or when splinting is impossible because of alveolar ridge atrophy and when splinting is not recommended for medical reasons or where adequate physiotherapy is impossible in bilateral or unilateral subcondylar fractures [28]. Also in bilateral condylar fractures associated with comminuted mid-facial fractures and bilateral subcondylar fractures with associated gnathologic problems, such as retrognathia or prognathism, open bite with periodontal problems or lack of posterior support, loss of multiple teeth and later need for elaborate reconstruction, bilateral condylar fractures with unstable occlusion due to orthodontics, and unilateral condylar fracture with unstable fracture base [28].

Avulsion or gross communition of condyle bone segments will require costochondral or sternoclavicular joint bone grafts and reconstruction plates for fixation [29]. The sternoclavicular graft does not have the demerit of hyperplastic growth is seen in costochondral grafts. Bone 
morphogenenic proteins, hydroxyappatite blocks and Beta TriCalcium phosphates, medpors (polyethelene) with or without hyaluronic acid are now available as alloplasts to minimize donor site mobilities [30]. The above treatment is also useful for old, malunited and non united fractures. After refracturing, debriding and freshening the bony ends, it is necessary to fill gap with cancellous chips and apply reconstruction plates. Condyle implants like the Lorenz or Christensens type are available for total joint replacements [29,30].

In conclusion, many of the fractures of the condyle of the mandible documented in this study were extracapsular and with medial overlap and, 81.8\% of our cases were managed by closed surgical treatment (IMF) while open surgical treatment (ORIF) was indicated in two (18.2\%) cases. The first was based on surgeon's choice and availability of funds to purchase the plates while the second was based on the presence of lateral overlap of the segments which may not be easily corrected by closed reduction. Conservative management was not indicated in any patient because there were obvious displacements which could be worsened by either mastication or rigorous jaw exercise without any form of fixation.

\section{REFERENCES}

[1] L. Dahlstrom, K. E. Kahnberg and L. Lindahl, “15 Years Follow-Up on Condylar Fractures,” International Journal of Oral and Maxillofacial Surgery, Vol. 18, No. 1, 1989, pp. 18-23. doi:10.1016/S0901-5027(89)80009-8

[2] P. A. Banks, "Pragmatic Approach to the Management of Condylar Fractures," International Journal of Oral and Maxillofacial Surgery, Vol. 27, No. 4, 1998, pp. 244-246. doi:10.1016/S0901-5027(05)80504-1

[3] R. R. Bos, R. P. Ward Booth and L. G. de Bont, "Mandibular Condyle Fractures: A Consensus,” British Journal of Oral and Maxillofacial Surgery, Vol. 37, No. 2, 1999, pp. 87-89. doi:10.1054/bjom.1998.0014

[4] A. O. Fasola, E. A. Nyako, A. E. Obiechina, et al., "Trends in the Characteristics of Maxillofacial Fractures in Nigeria,” Journal of Oral and Maxillofacial Surgery, Vol. 61, No. 10, 2003, pp. 1140-1143. doi:10.1016/S0278-2391(03)00671-2

[5] A. Alkan, M. Metin, M. Muglali, et al., "Biomechanical Comparison of Plating Techniques for Fractures of the Mandibular Condyle,” British Journal of Oral and Maxillofacial Surgery, Vol. 45, No. 2, 2007, pp. 145-149. doi:10.1016/j.bjoms.2006.04.011

[6] L. Asprino, S. Consani and M. De Moraes, “A Comparative Biomechanical Evaluation of Mandibular Condyle Fracture Plating Techniques,” Journal of Oral and Maxillofacial Surgery, Vol. 64, No. 3, 2006, pp. 452-456. doi:10.1016/j.joms.2005.11.017

[7] L. A. Assael, "Open versus Closed Reduction of Adult Mandibular Condyle Fractures: An Alternative Interpretation of the Evidence," Journal of Oral and Maxillofacial
Surgery, Vol. 61, No. 11, 2003, pp. 1333-1339. doi:10.1016/S0278-2391(03)00736-5

[8] M. Hawitschka and U. Ecklet, “Assessment of Patients Treated for Intra-Capsular Fractures of the Mandibular Condyle by Closed Techniques," Journal of Oral and Maxillofacial Surgery, Vol. 60, No. 7, 2002, pp. 784-791. doi:10.1053/joms.2002.33246

[9] M. L. R. Hlawitschka and U. Eckelt, "Functional and Radiological Results of Open and Closed Treatment If Intracapsular (Diacapitular) Condylar Fractures of the Mandible," International Journal of Oral and Maxillofacial Surgery, Vol. 34, No. 6, 2005, pp. 597-604. doi:10.1016/j.ijom.2005.02.004

[10] A. W. Baker, J. McMahon and K. F. Moss, "Current Consensus on the Management of Fractures of the Mandibular Condyle," International Journal of Oral and Maxillofacial Surgery, Vol. 27, No. 4, 1998, pp. 258-266. doi:10.1016/S0901-5027(05)80507-7

[11] J. Andersson, F. Hallmer and L. Eriksson, "Unilateral Mandibular Condylar Fractures: 31-Year Follow-Up of Non-Surgical Treatment,” International Journal of Oral and Maxillofacial Surgery, Vol. 36, No. 4, 2007, pp. 310314. doi:10.1016/j.ijom.2006.11.001

[12] V. S. Konstantinovic and B. Dimitrijevic, "Surgical versus Conservative Treatment of Unilateral Condylar Process Fractures: Clinical and Radiographic Evaluation of 80 Patients,” Journal of Oral and Maxillofacial Surgery, Vol. 50, No. 1, 1992, pp. 349-352. doi:10.1016/0278-2391(92)90395-G

[13] N. Hyde, M. Manisali and B. Aghabeigi, "The Role of Open Reduction and Internal Fixation in Unilateral Fractures of the Mandibular Condyle: A Prospective Study,” British Journal of Oral and Maxillofacial Surgery, Vol. 40, No. 1, 2002, pp. 19-22. doi:10.1054/bjom.2001.0734

[14] J. R. Hayward and F. C. Richard, "Fractures of Mandibular Condyle,” Journal of Oral and Maxillofacial Surgery, Vol. 51, No. 1, 1993, pp. 57-61. doi:10.1016/S0278-2391(10)80391-X

[15] M. T. Brandt and R. H. Haug “Open versus Closed Reduction of Adult Mandibular Condyle Fractures: A Review of the Literature Regarding the Evolution of Current Thoughts on Management," Journal of Oral and Maxillofacial Surgery, Vol. 61, No. 11, 2003, pp. 1324-1332. doi:10.1016/S0278-2391(03)00735-3

[16] S. K. Chakraborty, "Subcondylar Fracture. Open Reduction and Bone Plating," Medical Journal Armed Forces India, Vol. 63, No. 2007, pp. 85-87.

[17] B. H. Choi and J. H. Yoo, "Open Reduction of Condylar neck Fractures with Exposure of the Facial Nerve,” Oral Surgery, Oral Medicine, Oral Pathology, Oral Radiology and Endodontics, Vol. 88, No. 3, 1999, pp. 292-296. doi:10.1016/S1079-2104(99)70030-2

[18] B. H. Choi, C. K. Yi and J. H. Yoo, "Clinical Evaluation of 3 types of plate Osteosynthesis for Fixation of Condylar Neck Fractures,” Journal of Oral and Maxillofacial Surgery, Vol. 59, No. 7, 2001, pp. 734-737. doi:10.1053/joms.2001.24283

[19] J. Choi, N. Oh and I. K. Kim, “A Follow-Up Study of 
Condyle Fracture in Children," International Journal of Oral and Maxillofacial Surgery, Vol. 34, No. 8, 2005, pp. 851-858. doi:10.1016/j.ijom.2005.04.005

[20] U. Eckelt, M. Schneider, F. Erasmus, et al., “Open versus Closed Treatment of Fractures of the Mandibular Condylar Process-A Prospective Randomized Multi-Centre Study,” Journal of Cranio-Maxillofacial Surgery, Vol. 34, No. 5, 2006, pp. 306-314. doi:10.1016/j.jcms.2006.03.003

[21] F. W. Deleyiannis, L. Vecchione and B. Martin, "Open Reduction and Internal Fixation of Dislocated Condylar Fractures in Children: Long-Term Clinical and Radiologic Outcomes,” Annals of Plastic Surgery, Vol. 57, No. 5, 2006, pp. 495-501. doi:10.1097/01.sap.0000226943.79337.bf

[22] G. De Riu, U. Gamba and M. Anghinoni, “A Comparison of Open and Closed Treatment of Condylar Fractures: A Change in Philosophy," International Journal of Oral and Maxillofacial Surgery, Vol. 30, No. 5, 2001, pp. 384389. doi:10.1054/ijom.2001.0103

[23] M. Devlin, W. Hislop and A. Carton, "Open Reduction and Internal Fixation of Fractured Mandibular Condyles by a Retromandibular Approach: Surgical Morbidity and Informed Consent," British Journal of Oral and Maxillofacial Surgery, Vol. 40, No. 1, 2002, pp. 23-25. doi:10.1054/bjom.2001.0748

[24] R. H. Haug and M. T. Brandt, “Traditional versus Endoscope-Assisted Open Reduction with Rigid Internal Fixation (ORIF) of Adult Mandibular Condyle Fractures: A Review of Literature Regarding Current Thoughts on Management,” Journal of Oral and Maxillofacial Surgery
Vol. 62, No. 10, 2004, pp. 1272-1279. doi:10.1016/j.joms.2004.04.017

[25] E. Ellis, "Condylar Process Fractures of the Mandible," Facial Plastic Surgery, Vol. 16, No. 2, 2000, pp. 193-205. doi:10.1055/s-2000-12579

[26] E. Ellis and G. Throckmorton, "Facial Symmetry after Closed and Open Treatment of Fractures of the Mandibular Condylar Process,” Journal of Oral and Maxillofacial Surgery, Vol. 58, No. 7, 2000, pp. 719-728. doi:10.1053/joms.2000.7253

[27] E. Ellis and G. S. Throckmorton, "Treatment of Mandibular Condyle Process Fractures: Biological Considerations," Journal of Oral and Maxillofacial Surgery, Vol. 63, No. 1, 2005, pp. 115-134. doi:10.1016/j.joms.2004.02.019

[28] K. Ishihama, S. Iida and T. Kimura, "Comparison of Surgical and Nonsurgical Treatment of Bilateral Condylar fractures Based on Maximal Mouth Opening," Journal of Cranio-Maxillofacial Surgery, Vol. 25, No. 1, 2007, pp. 16-22.

[29] B. R. Davis, J. E. Powell and A. D. Morrison, "FreeGrafting of Mandibular Condyle Fractures: Clinical Outcomes in 10 Consecutive Patients," International Journal of Oral and Maxillofacial Surgery, Vol. 34, No. 8, 2005, pp. 871-876. doi:10.1016/j.ijom.2005.04.002

[30] U. Joos and J. Kleinheinz, "Therapy of condylar neck fractures," International Journal of Oral and Maxillofacial Surgery, Vol. 27, No. 4, 1998, pp. 247-254. doi:10.1016/S0901-5027(05)80505-3 